\title{
A contribuição da anatomia foliar para a taxonomia de Raddia Bertol. (Poaceae: Bambusoideae) ${ }^{1}$
}

\author{
Reyjane Patrícia de Oliveira ${ }^{2,5}$, Hilda Maria Longhi-Wagner ${ }^{3}$ e Kelly Regina Batista Leite ${ }^{2,4}$
}

Recebido em 29/06/2006. Aceito em 4/04/2007

\begin{abstract}
RESUMO - (A contribuição da anatomia foliar para a taxonomia de Raddia Bertol. (Poaceae: Bambusoideae). Raddia é um gênero de bambus herbáceos que inclui nove espécies ocorrentes no Brasil, uma delas encontrada também em áreas extra-brasileiras. A anatomia foliar de todas as espécies foi analisada em microscopia óptica e microscopia eletrônica de varredura, visando à obtenção de caracteres úteis para sua taxonomia. Espécies de outros gêneros de bambus herbáceos foram utilizadas para comparação. Não foram encontrados caracteres anatômicos exclusivos de Raddia, e os mesmos foram pouco relevantes para a delimitação das espécies dentro do gênero, separando às vezes, apenas grupos de espécies. Entre estes caracteres, destacaram-se, em corte transversal: forma da nervura central, posição do feixe vascular mediano, número de feixes vasculares adjacentes ao feixe mediano e a forma das células fusóides. A análise da epiderme em vista frontal (MEV) mostrou diferenças entre as espécies quanto à ocorrência, densidade e distribuição de papilas. Raddia megaphylla R.P. Oliveira \& Longhi-Wagner e R. guianensis (Brongn.) Hitchc. \& Chase apresentaram maior número de caracteres anatômicos exclusivos, entre as espécies estudadas. Um tipo de tricoma não registrado anteriormente para Bambusoideae foi encontrado em R. stolonifera R.P. Oliveira \& Longhi-Wagner.
\end{abstract}

Palavras-chave: anatomia, bambus, Bambusoideae, Olyreae, Raddia, Gramineae

\begin{abstract}
Leaf anatomy contribution to the taxonomy of Raddia Bertol. (Poaceae: Bambusoideae)). Raddia is an herbaceous bamboo genus with nine species in Brazil, one of which extends beyond Brazilian borders. The leaf anatomy of these species was analyzed using optical and scanning electron microscopy, in order to obtain useful characters for the taxonomy of the genus. Other herbaceous bamboos were used for comparison and no characters exclusive to Raddia were found. Leaf anatomy traits had little to do with species delimitation within the genus, sometimes separating only groups of species. Of these traits, the most important were as follows, in transverse section: form of the midrib, position of the intermediate vascular bundle, number of vascular bundles adjacent to the intermediate bundle and form of the fusoid cells. A surface view of the epidermis (SEM) showed differences among the species as regards occurrence, density and distribution of the papillae. Raddia megaphylla R.P. Oliveira \& Longhi-Wagner and $R$. guianensis (Brongn.) Hitchc. \& Chase had the largest number of exclusive characters of the species studied. A type of trichome unknown in Bambusoideae was recorded for $R$. stolonifera R.P. Oliveira \& Longhi-Wagner.
\end{abstract}

Key words: anatomy, bamboos, Bambusoideae, Olyreae, Raddia, Gramineae

\section{Introdução}

A taxonomia das gramíneas é baseada principalmente em caracteres morfológicos das espiguetas e inflorescências. Porém, diferenças na anatomia foliar têm se mostrado úteis na definição de grupos, especialmente subfamílias, onde vários caracteres são constantes e diagnósticos (Prat 1936; Brown 1958; Metcalfe 1960; Ellis 1987). Uma das treze subfamílias de Poaceae inclui os bambus (GPWG 2001; SanchezKen et al. 2007), gramíneas essencialmente florestais muito diversificadas nas áreas tropicais das Américas e Ásia (Judziewicz et al. 1999). A maior parte das espécies de bambus lenhosos é monocárpica plurianual, ou seja, as plantas apresentam crescimento vegetativo durante muitos anos e florescem uma só vez. Isso torna o uso de caracteres reprodutivos um fator limitante para a sua identificação e, por isso, muitos autores têm

\footnotetext{
Parte da tese de Doutorado da primeira Autora

2 Programa de Pós-Graduação em Botânica, Universidade Estadual de Feira de Santana, Departamento de Ciências Biológicas, BR 116N km 3, 44031-460 Feira de Santana, BA, Brasil

3 Universidade Federal do Rio Grande do Sul, Departamento de Botânica, Av. Bento Gonçalves 9500, prédio 43323, 91501-970 Porto Alegre, RS, Brasil

${ }^{4}$ Universidade Federal da Bahia, Instituto de Ciências Ambientais e Desenvolvimento Sustentável, Rua Prof. José Seabra s.n., 47805-100 Barreiras, BA, Brasil

5 Autor para correspondência: rpolliveira@yahoo.com
} 
analisado a anatomia foliar do grupo na busca de disponibilizar mais caracteres diagnósticos (Brandis 1907; Page 1947; Metcalfe 1956; Tateoka et al. 1959; Renvoize 1985; 1987; Calderón \& Soderstrom 1973; Soderstrom \& Ellis 1987).

Como resultado da classificação artificial empregada ao longo dos anos, em que Bambusoideae era uma subfamília considerada sensu lato (e.g. Clayton \& Renvoize 1986), algumas análises de anatomia foliar publicadas incluíram representantes de Anomochlooideae e Pharoideae, subfamílias aceitas atualmente como as "gramíneas basais" (Judziewicz et al. 1999; GPWG 2001). Além disso, incluíram membros de Ehrarthoideae, considerada como relacionada aos bambus herbáceos principalmente pela presença de caracteres anatômicos compartilhados, dentre eles o mesofilo não radiado, células fusóides e células invaginantes no clorênquima de alguns grupos, além de tricomas bicelulares do tipo panicóide (GPWG 2001).

A circunscrição atual de Bambusoideae compreende apenas duas tribos, Bambuseae e Olyreae, bem sustentadas em estudos filogenéticos (Zhang \& Clark 2000; GPWG 2001), correspondendo aos grupos informais "bambus lenhosos" e "bambus herbáceos", respectivamente. Os caracteres da anatomia foliar definidos para esta subfamília incluem: mesofilo com células fusóides bem desenvolvidas, células invaginantes ("arm cells") geralmente bem desenvolvidas e com paredes fortemente invaginadas, além da ausência de anatomia Kranz. Quanto à epiderme foliar, apresenta células buliformes adaxiais, tricomas bicelulares microscópicos do tipo panicóide e papilas abundantes (GPWG 2001). É importante salientar que estes caracteres anatômicos são utilizados para delimitar Bambusoideae do restante das gramíneas, mas não têm sido muito úteis para definir grupos como gêneros e espécies, principalmente quando utilizados isoladamente, conforme ressaltado por Soderstrom \& Ellis (1987).

Trabalhos envolvendo especificamente a anatomia foliar da tribo Olyreae são pouco freqüentes, mas mostram que este grupo apresenta caracteres que concordam com o "tipo bambusóide", envolvendo a presença de células fusóides e invaginantes no clorênquima (Calderón \& Soderstrom 1967; 1973; Renvoize 1985). Além disto, é mencionado na literatura que apresenta células silicosas tipicamente crenadas na epiderme, perpendiculares à lâmina foliar (Ellis 1987; Soderstrom \& Ellis 1987). A anatomia foliar de representantes de Olyreae foi estudada por Calderón
\& Soderstrom (1973), Paisooksantivatana (1992) e Renvoize (1985), este último com o objetivo de separar os gêneros desta tribo com base na estrutura anatômica.

Raddia Bertol. inclui nove espécies exclusivas de áreas florestais e amplamente distribuídas no Brasil, uma delas, R. guianensis (Brongn.) Hitchc., ocorrendo também em áreas extra-brasileiras (Oliveira et al. 2008). Apresenta muitos problemas de delimitação taxonômica e os caracteres vegetativos têm se revelado de grande importância na delimitação das espécies. Caracteres anatômicos de Raddia brasiliensis Bertol. foram analisados por Brandis (1907), Renvoize (1985) e Vieira et al. (2002), e os conceitos de anatomia do gênero, até então, se restringiam ao conhecimento desta única espécie.

Informações sobre a epiderme foliar em microscopia eletrônica de varredura (MEV) também têm revelado importantes informações taxonômicas em Poaceae (Palmer \& Tucker 1981), inclusive em níveis taxonômicos mais baixos, como infragenérico (Davila \& Clark 1990), e até infra-específico (Hilu 1984). Representantes de bambus foram analisados sob este ponto de vista por Amarasinghe \& Watson (1988) e Clark et al. (1989), incluindo apenas espécies de bambus lenhosos. Não foram encontrados estes dados para Raddia ou outros bambus herbáceos na literatura consultada.

O presente trabalho analisa os aspectos da anatomia foliar de todas as espécies de Raddia, com o objetivo de obter caracteres de valor taxonômico que possam auxiliar na delimitação das mesmas, e de analisar se existe associação entre a anatomia foliar e possíveis padrões ecológicos do gênero.

\section{Material e métodos}

Foi analisada a anatomia foliar de representantes de todas as nove espécies de Raddia em corte transversal, sob microscópio óptico, e a epiderme foliar, em microscopia eletrônica de varredura (MEV). A maior parte dos exemplares-testemunho está depositada no herbário da Universidade Estadual de Feira de Santana (HUEFS), porém materiais de outros herbários também foram utilizados, discriminados na Tab. 1 (acrônimos conforme Holmgren \& Holmgren 1998). Foram também analisadas espécies de outros nove gêneros de bambus herbáceos em corte transversal, para fins de comparação, estando os mesmos listados na Tab. 2. 


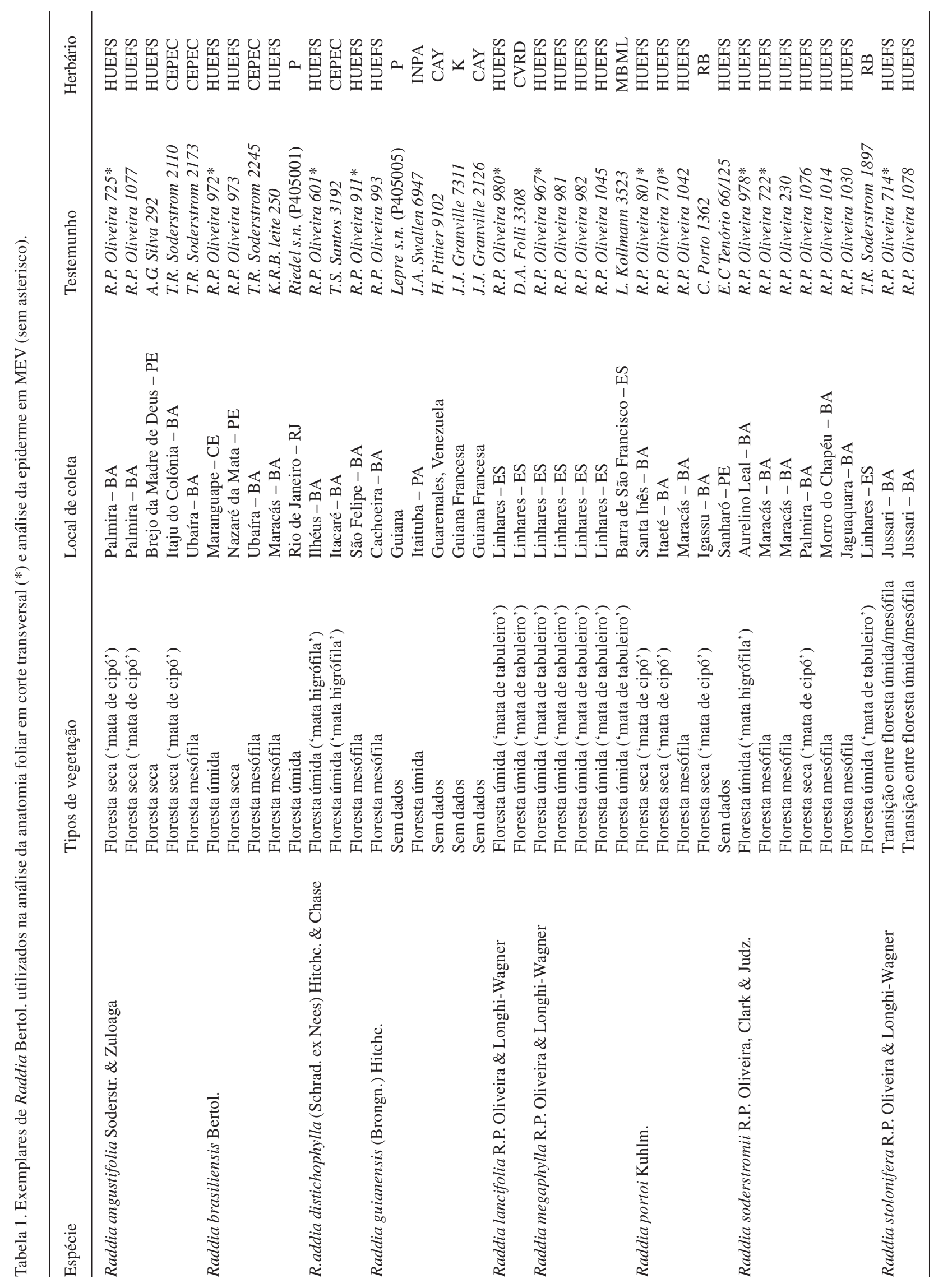


Tabela 2. Exemplares de outros gêneros da tribo Olyreae utilizados na análise da anatomia foliar em corte transversal.

\begin{tabular}{|c|c|c|c|}
\hline Espécie & Local de coleta & Testemunho & Herbário \\
\hline Arberella bahiensis Soderstr. \& Zuloaga & Barro Preto - BA & J.G. Jardim s.n. & HUEFS \\
\hline Cryptochloa capillata (Trin.) Soderstr. & Potiraguá - BA & B. M. Silva 80 & HUEFS \\
\hline Eremitis parviflora (Trin.) Calderón \& Soderstr. & Monte Pascoal-BA & R.P. Oliveira 575 & HUEFS \\
\hline Eremitis sp. & Jussari-BA & R.P. Oliveira 715 & HUEFS \\
\hline Lithachne pauciflora (Sw.) P. Beauv. & Maranguape-CE & R.P. Oliveira 970 & HUEFS \\
\hline Olyra bahiensis R.P. Oliveira \& Longhi-Wagner & Ilhéus-BA & R.P. Oliveira 712 & HUEFS \\
\hline O. caudata Trin. & Garotire - PA & A. Gely 433 & MG \\
\hline O. ciliatifolia Raddi & Palmira-BA & R.P. Oliveira 723 & HUEFS \\
\hline O. fasciculata Trin. & Itanhém - BA & W.W. Thomas 12345 & HUEFS \\
\hline O. filiformis Trin. & Una - BA & R.P. Oliveira 729 & HUEFS \\
\hline O. glaberrima Raddi & Santa Teresa-ES & $R$. Verveloet 2206 & HUEFS \\
\hline O. humilis Nees & Porto Alegre - RS & H.M. Longhi-Wagner 8001 & HUEFS \\
\hline O. latifolia $\mathrm{L}$. & Jussari-BA & R.P. Oliveira 713 & HUEFS \\
\hline O. latispicula Soderstr. \& Zuloaga & Monte Pascoal - BA & R.P. Oliveira 576 & HUEFS \\
\hline O. loretensis $\mathrm{Mez}$ & Manaus - AM & S.R. Lowrie 73 & INPA \\
\hline Pariana lanceolata Trin. & Itacaré - BA & R.P. Oliveira 681 & HUEFS \\
\hline Pariana multiflora R.P. Oliveira. Longhi-Wagner \& Hollowell & Santa Teresa-ES & R.P. Oliveira 849 & HUEFS \\
\hline Parodiolyra luetzelburgii (Pilg.) Soderstr. \& Zuloaga & Colider-PA & M.N. Silva 25 & INPA \\
\hline P. micrantha (Kunth) Zuloaga \& Davidse & Lençóis - BA & R.P. Oliveira 139 & HUEFS \\
\hline P. ramosissima (Trin.) Soderstr. \& Zuloaga & Itacaré- BA & R.P. Oliveira 688 & HUEFS \\
\hline Raddiella esenbeckii (Steud.) Calderón \& Soderstr. & Mata de São João - BA & R.P. Oliveira 664 & HUEFS \\
\hline Sucrea maculata Soderstr. & Santa Teresa-ES & R.P. Oliveira 851 & HUEFS \\
\hline S. monophylla Soderstr. & Jussari-BA & R.P. Oliveira 716 & HUEFS \\
\hline
\end{tabular}

Para a análise da anatomia em corte transversal foi utilizada a porção mediana basal da segunda lâmina foliar abaixo da inflorescência. A maior parte do material utilizado nesta análise foi obtida em seu ambiente natural, onde as lâminas foliares inteiras foram fixadas em FAA $70 \%$ e posteriormente conservadas em álcool 70\% (Johansen 1940). Quando necessário, também foi utilizado material de herbário reidratado. Para tanto, o material foi fervido em água e glicerina (50\%) e levado posteriormente à estufa a $50{ }^{\circ} \mathrm{C}$, permanecendo por aproximadamente um mês para amolecimento dos tecidos. Os materiais reidratados foram fixados em álcool 70\%, e assim mantidos até o momento do corte.

Foram feitos cortes anatômicos à mão livre, corados com azul de astra e safranina (Roeser 1972), e montadas lâminas semi-permanentes, com gelatina glicerinada. Para alguns materiais com folhas mais silicificadas foi utilizado o processo de emblocamento em historesina, sendo os cortes posteriormente corados com hematoxilina e as lâminas montadas em entellan (Macêdo 1997). As lâminas foram observadas em microscópio óptico Zeiss e fotomicrografadas em câmera digital Olympus, acoplada ao microscópio. A terminologia empregada seguiu principalmente Calderón \& Soderstrom (1973) e Ellis (1976; 1979).

Para a análise da superfície da epiderme em microscópio eletrônico de varredura foram utilizadas lâminas foliares de materiais de herbário, sem prétratamento. Foram utilizados pedaços de $1 \times 1 \mathrm{~cm}$, à altura da região mediana das lâminas, para observação nas duas faces (abaxial e adaxial). Estes cortes foram montados em pequenos cilindros de aço com fita adesiva metálica e posteriormente recobertos com ouro em sputter Balzers SCD 050. As amostras assim preparadas foram analisadas e elétron-fotomicrografadas em microscópio eletrônico de varredura LEO 1430VP. Para esta análise foi empregada a terminologia de Palmer \& Tucker (1981).

As espécies estudadas ocorrem principalmente ao longo da Mata Atlântica, a qual apresenta diferentes fisionomias, condicionadas por diferenças hídricas e edáficas, incluindo basicamente florestas ombrófilas e estacionais, segundo a classificação de Veloso et al. (1991). Procurou-se relacionar os padrões anatômicos observados aos locais de coleta dos materiais e aos tipos florestais referidos por Peixoto \& Silva (1997), Prado (2000) e Thomas (2003). 


\section{Resultados e discussão}

Nas espécies de Raddia (Fig. 1-6), as folhas são pseudopecioladas, assim como na maior parte dos bambus (GPWG 2001). São fortemente assimétricas no ápice e na base, caracteristicamente apiculadas, e variam bastante em tamanho e forma, desde linearlanceoladas $(R$. angustifolia Soderstr. \& Zuloaga e $R$. guianensis (Brongn.) Hitchc.) até largamente ovais (R. megaphylla R.P. Oliveira \& Longhi-Wagner). Raddia soderstromii R.P. Oliveira, Clark \& Judz. comumente apresenta folhas com coloração vinácea, especialmente na face abaxial, o que também foi registrado raramente para $R$. brasiliensis. Essa coloração é comum a outros representantes de bambus herbáceos, dentre eles Diandrolyra bicolor Stapf, e espécies de Eremitis Döll, Pariana Aubl. e Cryptochloa Swallen (Soderstrom 1982). Soderstrom (1982) observou, a partir de materiais de $R$. soderstromii (citada como Raddia $\mathrm{sp}$.), que esta coloração ocorre em virtude da presença de antocianinas confinadas à face abaxial da lâmina.

De acordo com a classificação de Ellis (1976), as folhas de Raddia são expandidas e relativamente planas, estando normalmente abertas em condições favoráveis. Entretanto, sob condições de estresse, a maioria delas costuma se dobrar rapidamente ao longo da nervura central, ou até mesmo se enrolar, por exemplo, quando a planta é retirada do solo ou quando exposta ao calor intenso.

Os caracteres anatômicos analisados nas folhas das nove espécies de Raddia, que demonstraram importância taxonômica, estão discriminados na Tab. 3.

Epiderme - A estrutura da epiderme foliar em vista frontal (MEV) pode ser observada nas figuras 7-29. As células epidérmicas são arranjadas em fileiras longitudinais e estão distribuídas em zonas costais (sobre os feixes vasculares) e intercostais (entre eles), conforme ocorre nas demais gramíneas. A epiderme apresenta células longas intercaladas por células curtas. Todas as espécies de Raddia apresentam uma cutícula espessa recobrindo a epiderme, além de papilas geralmente densas na face abaxial, dificultando a clara visualização das paredes anticlinais. Quando visíveis, as mesmas revelaram-se sinuosas (Fig. 11), conforme anteriormente referido para Raddia brasiliensis (Vieira et al. 2002).

As células curtas podem ser suberosas ou silicificadas. Estas últimas são abundantes nas duas faces da epiderme e incluem os corpos silicosos. $\mathrm{O}$ formato dos corpos silicosos é tipicamente cruciforme nas zonas costais e crenado nas zonas intercostais (Fig. 18-19). Na face abaxial, muitas vezes são obscurecidos pela grande densidade de papilas. Células curtas com corpos silicosos crenados foram classificadas por Calderón \& Soderstrom $(1967 ; 1973)$ como "células silicosas oliróides", por serem típicas desta tribo, correspondendo ao tipo crenado-vertical de Palmer \& Tucker (1981). De acordo com Piperno \& Pearsal (1998), em Bambusoideae existe uma grande variação no tipo de corpos silicosos diagnósticos em nível de tribo, subtribo e gênero, indicando para Olyreae várias formas que são versões irregulares de complexos bilobados e cruciformes. Representantes de Raddia não foram analisados por estes autores, porém os corpos silicosos classificados no tipo "crenado-irregular" e referidos por estes autores para Maclurolyra tecta Calderón \& Soderstr. são os que mais se assemelham com aqueles que ocorrem em Raddia (Fig. 9). Renvoize (1985) já havia referido este tipo de corpo silicoso para estes dois gêneros, e a referida morfologia foi amplamente observada em todas as espécies de Raddia aqui analisadas.

Papilas grandes e cônicas foram referidas para a epiderme de Raddia por Calderón \& Soderstrom (1967). A presença, distribuição e morfologia destas papilas constituem-se em importantes caracteres taxonômicos neste gênero. As papilas estão localizadas sobre as células longas, em geral de uma a três em cada célula, muitas vezes associadas aos estômatos (Fig. 20, 23). Ocorrem na face abaxial de todas as espécies analisadas, porém em $R$. angustifolia, $R$. portoi Kuhlm e $R$. guianensis são encontradas também na face adaxial (Fig. 7, 13). Podem ocorrer apenas na região epidérmica acima dos feixes vasculares, ou em toda a superfície, com variações entre as espécies (Tab. 3). Papilas deste tipo foram anteriormente referidas para vários bambus herbáceos (Soderstrom \& Calderón 1973; Renvoize 1985; Paisooksantivatana 1992), dentre eles Raddia brasiliensis (Vieira et al. 2002), e também para alguns bambus lenhosos (Clark et al. 1989). É interessante salientar que estas papilas epidérmicas estão ausentes nas gramíneas basais (GPWG 2001). O padrão de distribuição das papilas referido por Vieira et al. (2002) para a face abaxial de $R$. brasiliensis, "densamente agrupadas em faixas laterais às zonas costais", foi confirmado para esta espécie e também observado em $R$. soderstromi, $R$. megaphylla, $R$. lancifolia R.P. Oliveira \& Longhi-Wagner. Em R. guianensis as papilas estão densamente agrupadas entre si e são, 

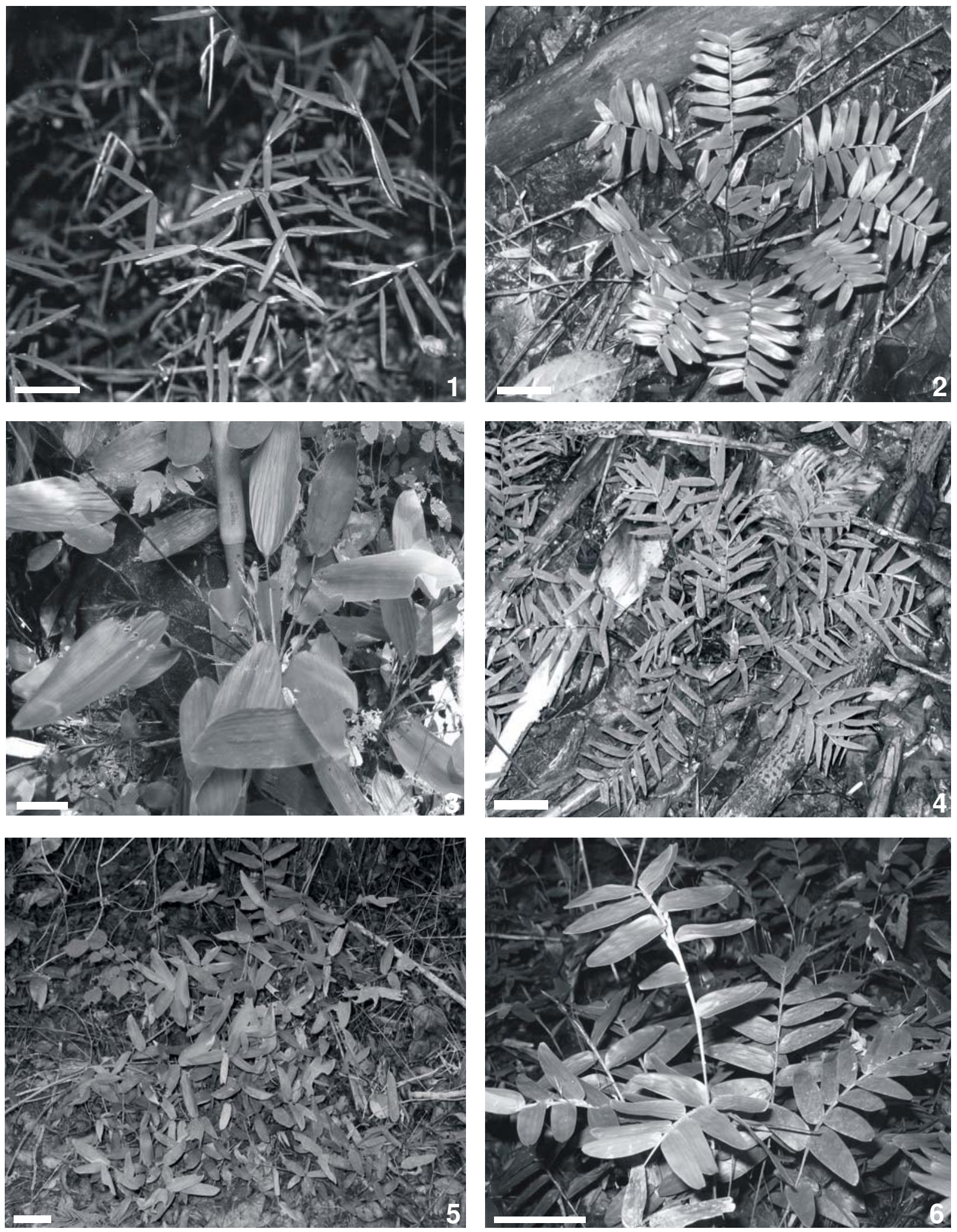

Figuras 1-6. 1. Aspecto geral de Raddia angustifolia Soderstr. \& Zuloaga crescendo em mata de cipó (Palmira, Bahia). 2. Raddia guianensis (Brongn.) Hitchc. em mata mesófila (Cachoeira, Bahia). 3. Raddia megaphylla R.P. Oliveira \& Longhi-Wagner em mata de tabuleiro (Itamaraju, Bahia). 4. Raddia portoi Kuhlm. crescendo em mata mesófila (Cachoeira, Bahia). 5. Raddia soderstromii R.P. Oliveira, Clark \& Judz. em mata mesófila (Coração de Maria, Bahia). 6. Raddia stolonifera R.P. Oliveira \& Longhi-Wagner em mata mesófila (Jussari, Bahia). Barras $=5 \mathrm{~cm}$. 
Acta bot. bras. 22(1): 1-19. 2008.

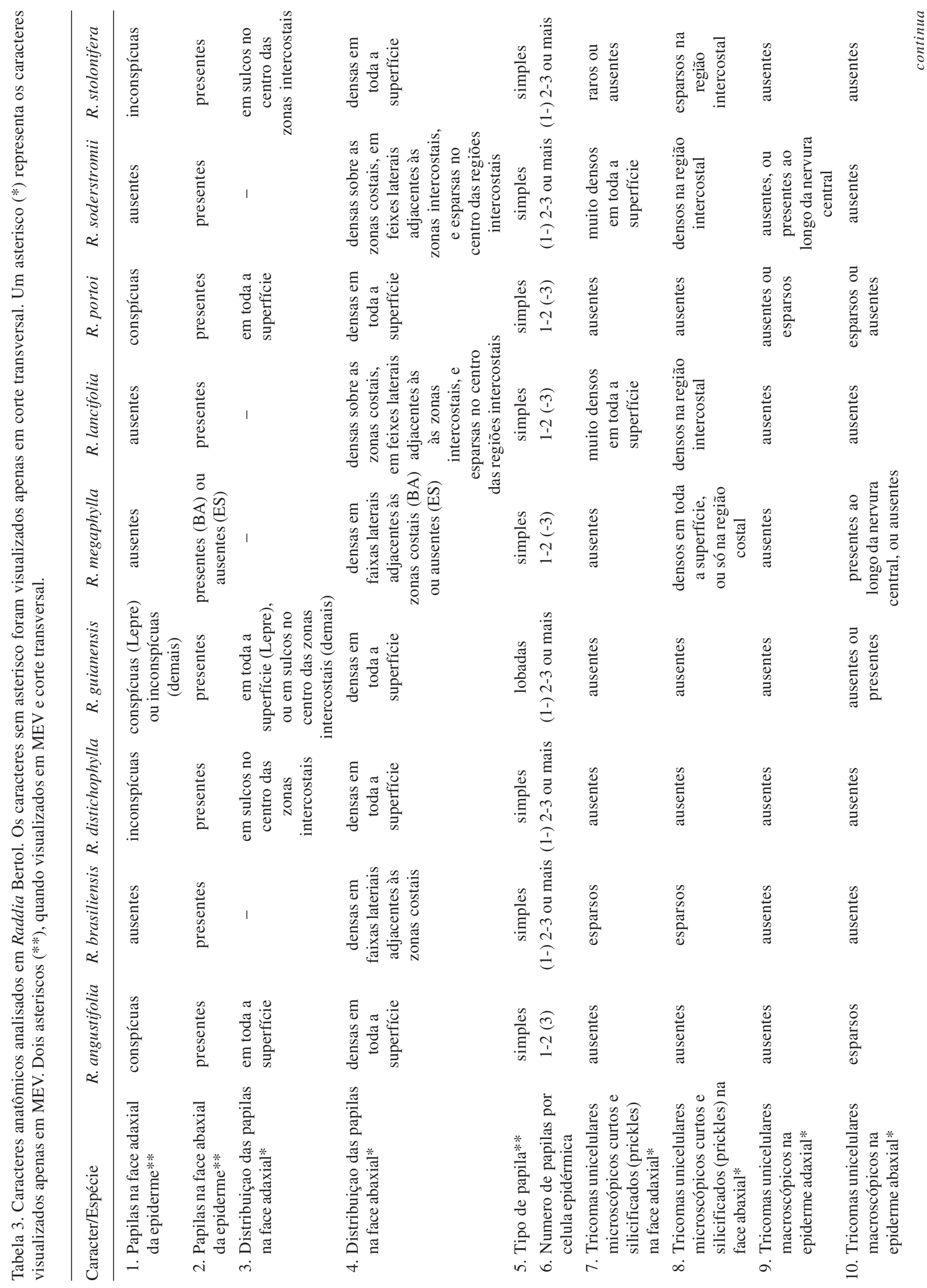




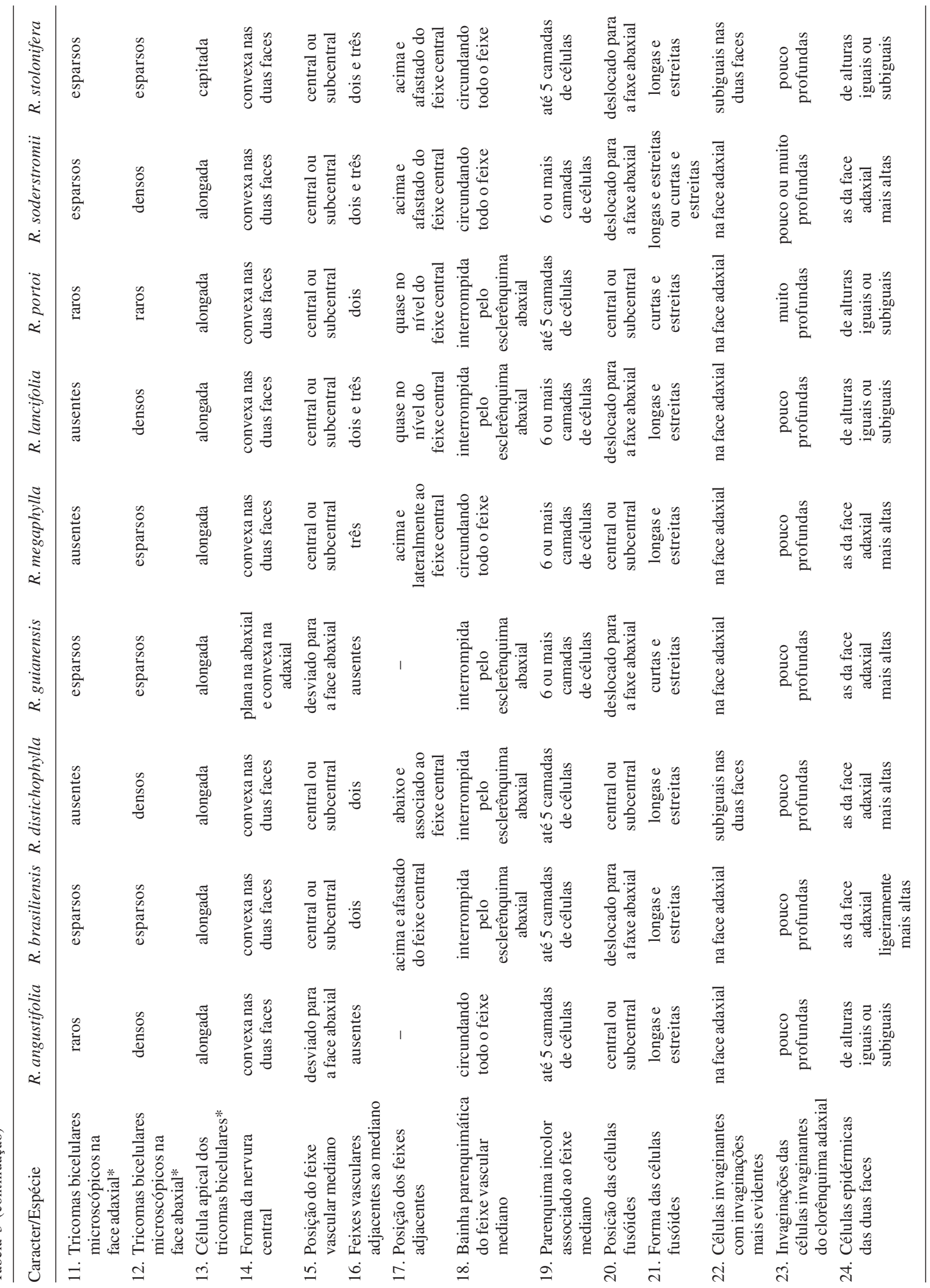



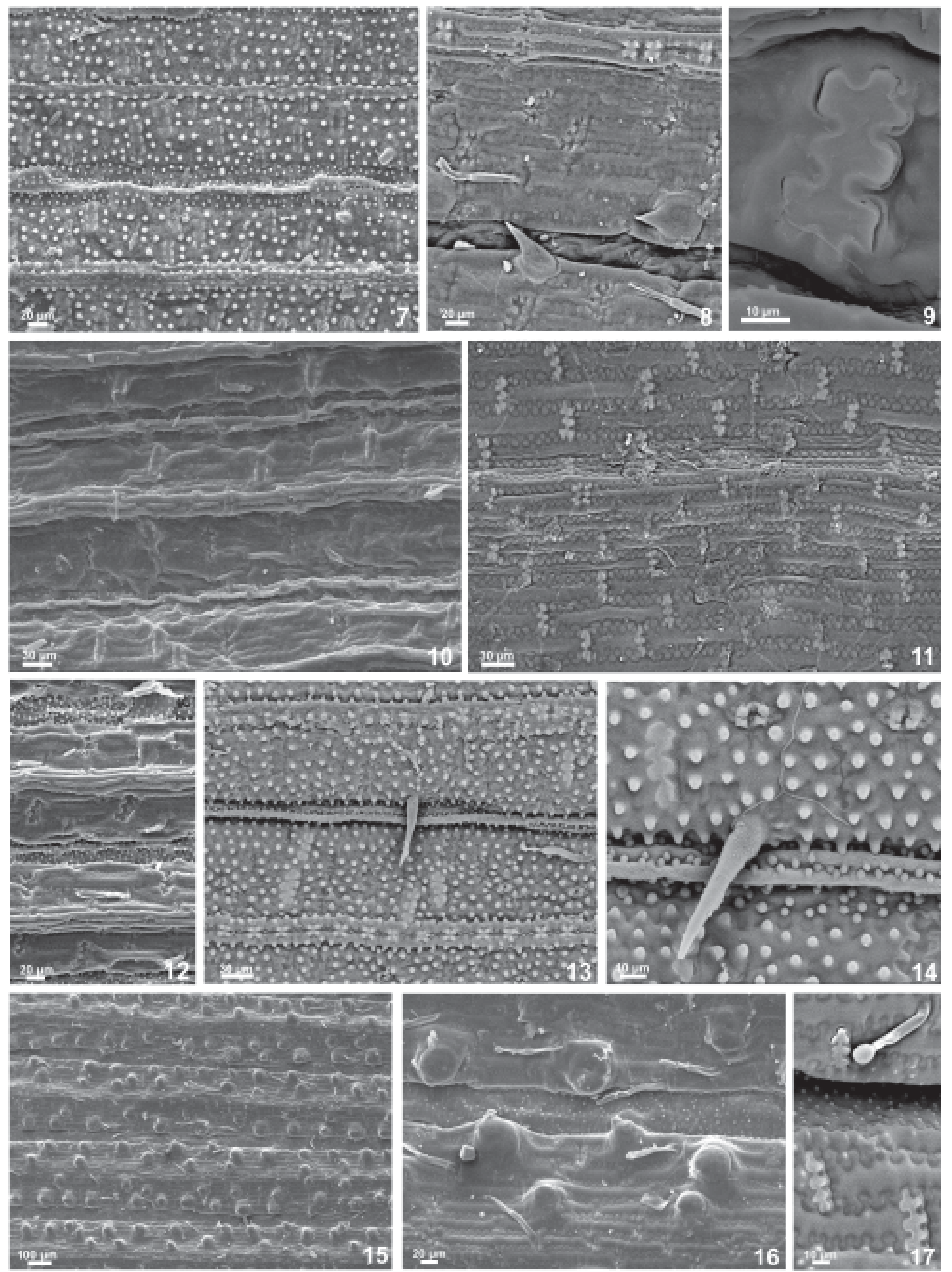

Figuras 7-17. Face adaxial da epiderme foliar de espécies de Raddia Bertol. 7. Raddia angustifolia Soderstr. \& Zuloaga: papilas densas recobrindo toda a epiderme. 8. Raddia brasiliensis Bertol.: tricomas unicelulares curtos e tricomas bicelulares tipo panicóide; corpos silicosos cruciformes sobre os feixes e crenados entre eles. 9-10. Raddia distichophylla (Schrad. ex Nees) Chase: 9. Corpo silicoso crenado. 10. Epiderme lisa sem papilas. 11. Raddia megaphylla R.P. Oliveira \& Longhi-Wagner: paredes anticlinais sinuosas. 12. Raddia lancifolia R.P. Oliveira \& Longhi-Wagner: cutícula espessa recobrindo a epiderme. 13-14. Raddia portoi Kuhlm.: 13. Papilas e tricoma unicelular longo. 14. Estômatos e tricoma unicelular longo. 15-16. Raddia soderstromii R.P. Oliveira, Clark \& Judz.: 15. Epiderme recoberta por tricomas unicelulares curtos. 16. Tricomas bicelulares tipo panicóide e tricomas unicelulares curtos. 17. Raddia stolonifera R.P. Oliveira \& Longhi-Wagner: tricoma bicelular com célula apical capitada; corpo silicoso crenado. 

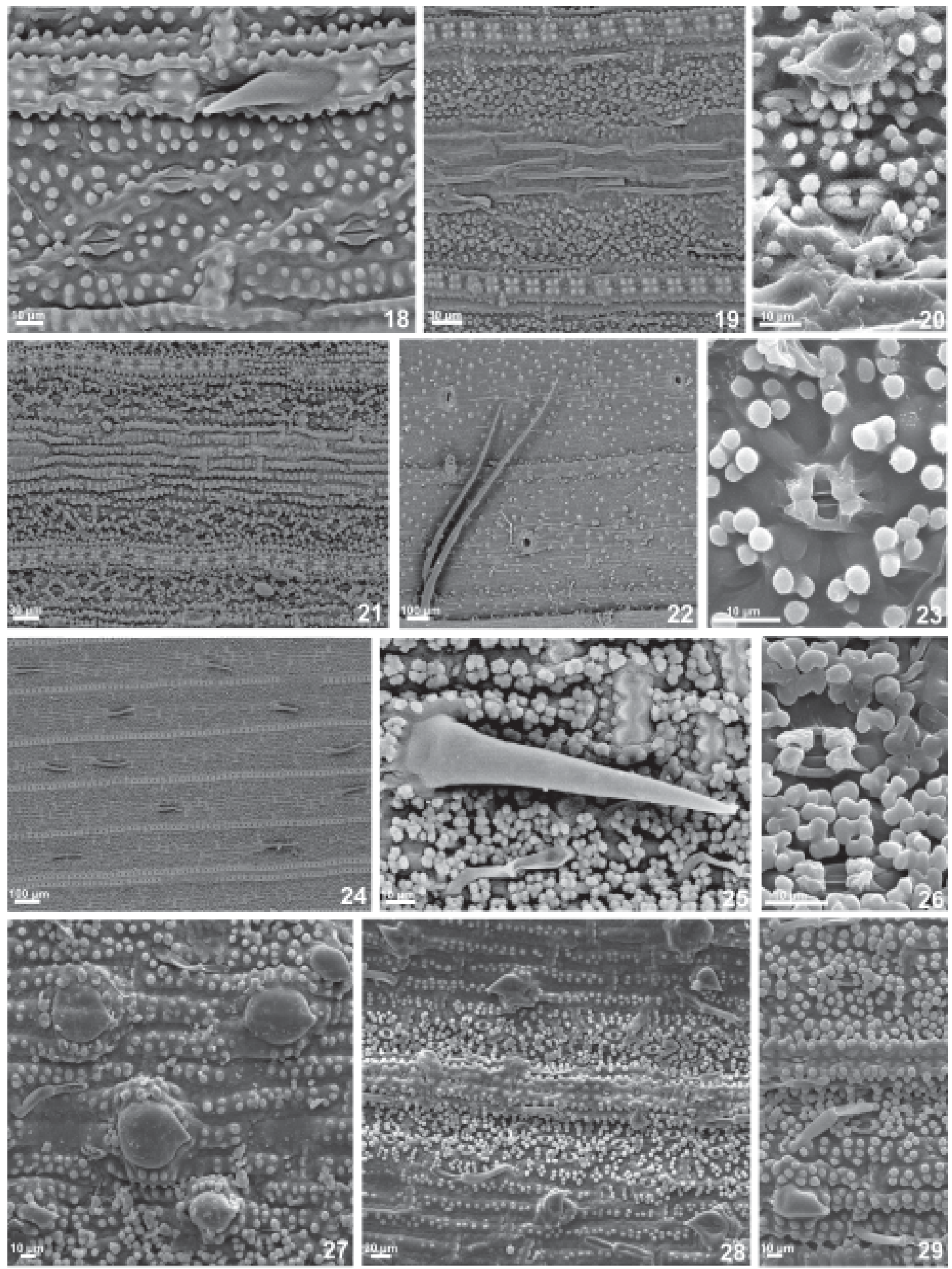

Figuras 18-29. Face abaxial da epiderme foliar de espécies de Raddia. 18. Raddia angustifolia Soderstr. \& Zuloaga: corpos silicosos cruciformes sobre os feixes e crenados entre eles. 19-20. Raddia brasiliensis Bertol.: 19. Papilas densas distribuídas lateralmente às zonas costais. 20. Estômato circundado por papilas; tricoma unicelular curto. 21. Raddia distichophylla (Schrad. ex Nees) Chase: epiderme totalmente recoberta por papilas. 22-23. Raddia megaphylla R.P. Oliveira \& Longhi-Wagner: 22. Tricoma unicelular longo e flexível. 23. Estômato circundado por papilas. 24-26. Raddia guianensis (Brongn.) Hitchc.: 24. Epiderme recoberta por papilas e numerosos tricomas unicelulares longos e rígidos. 25. Detalhe dos tricomas longos e dos tricomas bicelulares tipo panicóide. 26. Papilas lobadas rodeando o estômato. 27. Raddia lancifolia R.P. Oliveira \& Longhi-Wagner: tricomas unicelulares curtos rodeados por papilas. 28. Raddia soderstromii R.P. Oliveira, Clark \& Judz.: vista geral da epiderme. 29. Raddia stolonifera R.P. Oliveira \& Longhi-Wagner: papilas e tricomas (unicelular e bicelular). 
em sua maioria, levemente lobadas (Fig. 25-26). As demais espécies de Raddia apresentam papilas simples.

Os estômatos estão distribuídos nas zonas intercostais, em fileiras laterais às zonas costais. Todas as espécies de Raddia revelaram-se hipoestomáticas, com exceção de $R$. portoi, que apresenta estômatos também na face adaxial (Fig. 13-14), os quais são menos numerosos. Vieira et al. (2002) indicaram a presença de estômatos nas duas faces da lâmina foliar de $R$. brasiliensis, o que não foi encontrado nos materiais aqui analisados. Os estômatos podem estar rodeados por papilas densamente agrupadas em torno dos mesmos, como em $R$. distichophylla (Schrad. ex Nees) Chase (Fig. 20), ou não (em $R$. angustifolia), ou podem ainda apresentar as duas condições (R. portoi). A presença de papilas muito densas adjacentes aos estômatos por vezes dificulta a clara definição do tipo estomático, mas em todas as espécies estão presentes estômatos paracíticos. Os estômatos estão localizados em pequenas depressões em relação às demais células epidérmicas ( $R$. distichophylla $\mathrm{e}$ $R$. stolonifera R.P. Oliveira \& Longhi-Wagner), ou no mesmo nível destas (Fig. 35) (R. brasiliensis, $R$. guianensis, $R$. portoi, $R$. soderstromii, $R$. lancifolia, $R$. megaphylla).

Tricomas microscópicos unicelulares, curtos e silicificados ("prickle-hairs") estão presentes ao longo das margens das lâminas foliares de todas as espécies estudadas, e também foram referidos para espécies de Lithachne P. Beauv (Paisooksantivatana 1992). Com exceção de Raddia angustifolia, $R$. portoi, $R$. distichophylla e $R$. guianensis, estes tricomas também podem ocorrer ao longo da nervura central e zonas costais e/ou intercostais das duas faces da epiderme, sendo mais numerosos na face abaxial. Em $R$. soderstromii e $R$. lancifolia (Fig. 27-28) esses tricomas são muito abundantes e praticamente substituem as papilas. Em R. megaphylla, tanto podem ser abundantes (Oliveira 967) (Fig. 22), quanto estar praticamente ausentes (Oliveira 1045), em materiais oriundos de populações diferentes. Tricomas unicelulares macroscópicos podem também estar presentes em algumas espécies, principalmente na face abaxial, sendo longos e híspidos em $R$. guianensis (Fig. 25), o que torna a lâmina foliar distintivamente áspera ao tato. Nas demais espécies, os mesmos são mais curtos e flexíveis, ou estão ausentes. Em $R$. angustifolia e $R$. portoi ocorrem tanto na face abaxial quando na adaxial.
Tricomas bicelulares microscópicos ("microhairs") estão presentes nas duas faces da epiderme, sendo mais densos na face abaxial (Fig. 25, 28-29) do que na adaxial (Fig. 16). Correspondem ao tipo "panicóide" de Prat (1936), e são amplamente registrados entre os bambus (Calderón \& Soderstrom 1973). Este tipo de tricoma apresenta a célula basal menor que a apical, ambas estreitas e alongadas, sendo a apical aguda. Em Raddia stolonifera, entretanto, foram observados tricomas com a célula basal muito mais longa que a apical, e esta arredondada (Fig. 17), correspondendo ao tipo "Enneapogon" citado por Amarasinghe \& Watson (1998) e referido para Pappophorum elegans Nees ex Steud. (Chloridoideae) por Tateoka et al. (1959). O registro deste tipo de tricoma representa uma novidade tanto para Raddia, quanto para a subfamília Bambusoideae.

Em corte transversal da lâmina foliar (Fig. 30-48), a epiderme apresenta-se uniestratificada e com as células da face adaxial ligeiramente mais altas do que as da face abaxial (Fig. 34), ou de altura relativamente semelhante nas duas faces (Fig. 36). Vieira et al. (2002) não encontraram diferenças nestes caracteres entre as espécies de Olyreae estudadas (Raddia brasiliensis e Cryptochloa capillata (Trin.) Soderstr.). A análise anatômica de outros gêneros dessa tribo, no presente trabalho, demonstrou variação neste caráter também em representantes de Pariana Tutin e Parodiolyra Soderstr. \& Zuloaga, nos quais as células da face adaxial são geralmente mais altas do que as da abaxial. $\mathrm{Na}$ face adaxial da epiderme ocorrem grupos de células buliformes distribuídos ao longo de toda a extensão da lâmina foliar, entre os feixes vasculares (Fig. 30-33). Estas células estão ausentes na face abaxial e na região da nervura central, e são características para vários outros grupos de gramíneas (Ellis 1976). Todas as espécies de Raddia apresentaram diferenciação considerável entre as células buliformes e as demais células epidérmicas (Fig. 30-34, 36-39). O formato destas células pode variar, ocorrendo desde células completamente ovais até tendendo à forma arredondada. O bordo foliar pode apresentar fibras esclerenquimáticas (Fig. 40-41), ou não (Fig. 42).

Mesofilo - Em todas as espécies de Raddia, como nas demais gramíneas, o mesofilo não é diferenciado em parênquima paliçádico e lacunoso. O clorênquima nas espécies estudadas é tipicamente bambusóide (Calderón \& Soderstrom 1973; Renvoize 1985), com células invaginantes (Fig. 34) e células fusóides associadas aos feixes vasculares de primeira e segunda 

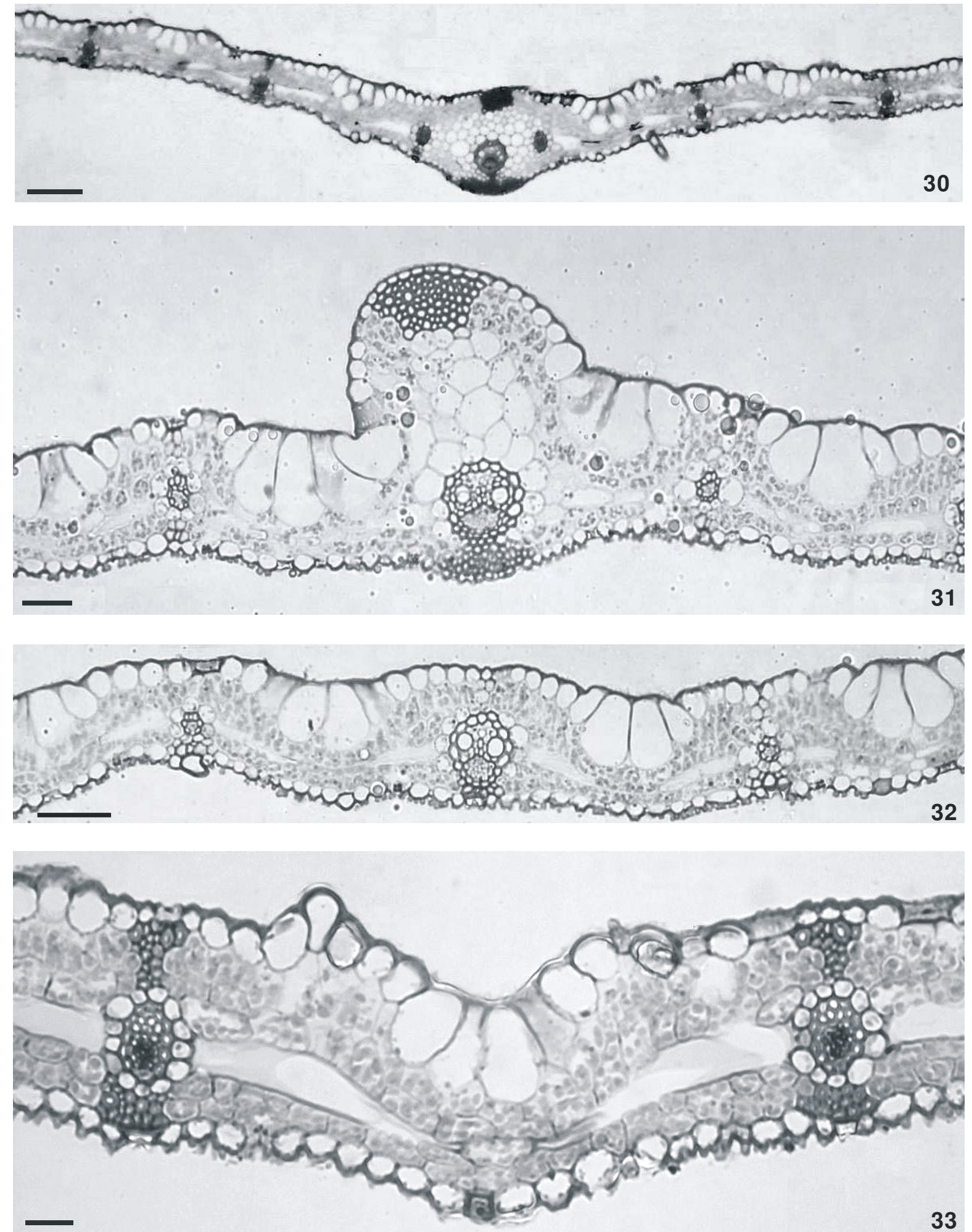

Figuras 30-33. Lâmina foliar em corte transversal. 30. Raddia stolonifera R.P. Oliveira \& Longhi-Wagner (vista geral). 31-32. Raddia guianensis (Brongn.) Hitchc.: 31. Feixe mediano fortemente deslocado para a face abaxial. 32. Feixes de primeira e segunda ordens alternados por conjuntos de células buliformes na epiderme. 33. Raddia lancifolia R.P. Oliveira \& Longhi-Wagner: epiderme formando sulcos na região das células buliformes. Barras $=50 \mu \mathrm{m}$. 

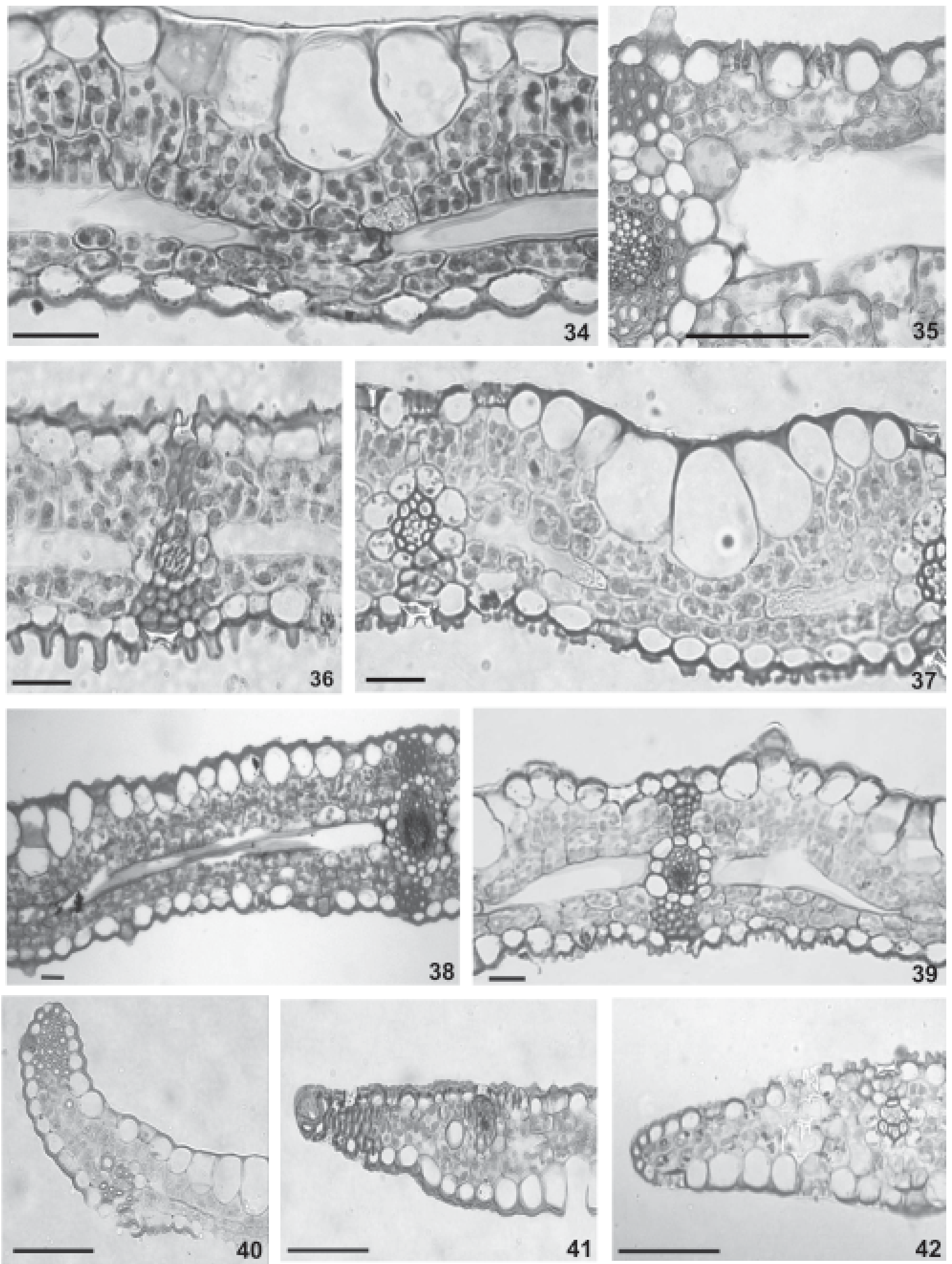

Figuras 34-42. Lâmina foliar em corte transversal. 34. Raddia soderstromii R.P. Oliveira, Clark \& Judz.: células buliformes bem desenvolvidas; células invaginantes e fusóides. 35. Raddia megaphylla R.P. Oliveira \& Longhi-Wagner: estômatos na face abaxial da epiderme. 36. Raddia portoi Kuhlm.: papilas nas duas faces epidérmicas. 37. Raddia guianensis (Brongn.) Hitchc.: células fusóides curtas associadas aos feixes secundários. 38. Raddia megaphylla R.P. Oliveira \& Longhi-Wagner: células fusóides longas e estreitas; células braciformes. 39. Raddia lancifolia R.P. Oliveira \& Longhi-Wagner: células fusóides retangulares. 40. Raddia angustifolia Soderstr. \& Zuloaga: Bordo da lâmina foliar. 41. Raddia brasiliensis Bertol.: Bordo da lâmina foliar. 42. Raddia guianensis (Brongn.) Hitchc.: Bordo da lâmina foliar. Barras $=50 \mu \mathrm{m}$. 

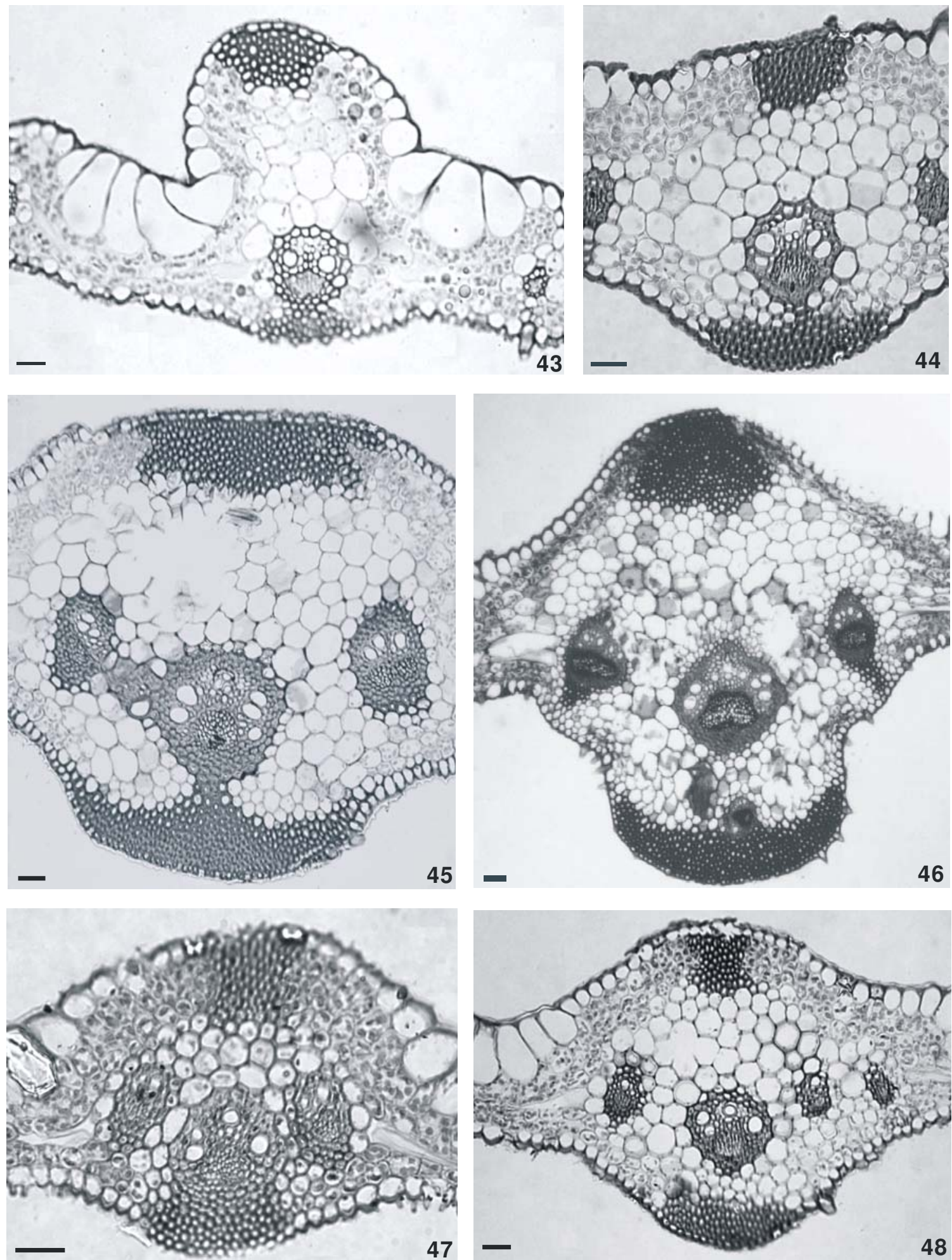

Figuras 43-48. Região da nervura central da lâmina foliar em corte transversal. 43. Raddia guianensis (Brongn.) Hitchc.: nervura central proeminente na face adaxial, sem feixes vasculares adjacentes. 44. Raddia brasiliensis Bertol.: nervura central convexa nas duas faces, com dois feixes adjacentes. 45. Raddia lancifolia R.P. Oliveira \& Longhi-Wagner: esclerênquima abaxial interrompendo a bainha do feixe mediano, com dois feixes adjacentes. 46. Raddia megaphylla R.P. Oliveira \& Longhi-Wagner: feixe mediano com três feixes adjacentes, dois acima e um abaixo. 47. Raddia portoi Kuhlm.: parênquima incolor associado ao feixe mediano com menos de cinco camadas de células. 48. Raddia stolonifera R.P. Oliveira \& Longhi-Wagner: feixe mediano com três feixes adjacentes laterais. Barras $=50 \mu \mathrm{m}$. 
ordens (Fig. 32-39). As células invaginantes estão posicionadas acima e abaixo das células fusóides, apresentando-se em uma ou duas camadas na face adaxial, e apenas uma na abaxial. A maioria das espécies apresenta células invaginantes com invaginações mais profundas na face adaxial, excetuando-se $R$. distichophylla e $R$. stolonifera, com células subiguais nas duas porções do mesofilo. De modo geral, as invaginações nessas células são pouco profundas. Entretanto, R. portoi apresenta células com invaginações muito profundas e em $R$. soderstromii podem ocorrer os dois tipos.

O comprimento e a forma das células fusóides podem variar entre as espécies de Raddia. Apenas em $R$. guianensis estas células são muito mais curtas do que nas demais espécies (Fig. 37). Raddia megaphylla apresenta células fusóides longas e estreitas (Fig. 38), enquanto em R. lancifolia estas são longas e largas (Fig. 39). Estes caracteres também foram considerados de valor taxonômico para espécies de outros gêneros de Olyreae, entre eles Piresia Swallen e Olyra L. (Calderón \& Soderstrom 1967). Renvoize (1985) referiu ausência de células fusóides para Raddiella esenbeckii (Steud.) Calderón \& Soderstr., mas no material aqui analisado, células fusóides bem desenvolvidas foram registradas para esta espécie.

Apesar do padrão anatômico apresentado pelo mesofilo das espécies de Raddia ser considerado característico dos bambus, alguns dos tipos de células mencionados acima podem aparecer em outras gramíneas C3, representantes das subfamílias Anomochlooideae, Pharoideae, Puellioideae, Ehrarthoideae e Arundinoideae (GPWG 2001). Células fusóides podem ainda, muito ocasionalmente, ocorrer em representantes da subfamília Panicoideae, como em espécies de Homolepis Chase (Watson et al. 1985 apud Ellis 1987) e em Streptostachys asperifolia Desv. (Morrone \& Zuloaga 1991), esta última também apresentando células invaginantes.

Sistema vascular - Os feixes vasculares nas espécies de Raddia são semelhantes aos encontrados nas demais Olyreae. Estes feixes constituem as zonas costais das lâminas foliares e são separados pelas zonas intercostais, onde se encontram as células fusóides e as células buliformes. Os feixes são circundados por duas bainhas: uma interna, com células de paredes esclerificadas, a bainha mestomática, e a outra mais externa, parenquimática. Feixes de primeira e segunda ordens em geral ocorrem em um mesmo nível, com pouca variação na posição em relação às faces adaxial e abaxial da epiderme (Fig. 30). Apenas um feixe vascular de segunda ordem está presente entre os de primeira ordem (Fig. 31). Cordões de esclerênquima subepidérmicos ocorrem na face adaxial em direção aos feixes de primeira e segunda ordens, interrompendo as duas bainhas perivasculares. $\mathrm{Na}$ face abaxial, as fibras esclerenquimáticas interrompem as bainhas apenas nos feixes de primeira ordem, em todas as espécies. Isso difere do padrão verificado nas espécies de Sucrea Soderstr. (Olyreae), nas quais as bainhas dos feixes não são interrompidas pelo esclerênquima.

Região da nervura central - As espécies de Raddia apresentam lâminas foliares com nervura central bem definida, em geral proeminente e convexa nas duas faces (Fig. 43-48). Essa morfologia também foi verificada em materiais analisados de Cryptochloa capillata, Parodiolyra ramosissima (Trin.) Soderstr. \& Zuloaga, Olyra latifolia L., O. fasciculata Trin. e Lithachne pauciflora (L.) P. Beauv. (Olyreae). Porém, em Raddia guianensis a nervura central é mais proeminente na face adaxial (Fig. 43), conforme observado também nos materiais analisados de Sucrea, além de Parodiolyra micrantha (Kunth) Zuloaga \& Davidse e várias espécies de Olyra (O. bahiensis R.P. Oliveira \& Longhi-Wagner, O. ciliatifolia Raddi, O. glaberrima Raddi, O. latispicula Soderstr. \& Zuloaga e $O$. loretensis Mez).

$\mathrm{O}$ feixe mediano da nervura central pode estar deslocado para a face abaxial da epiderme, em maior (Raddia guianensis) ou menor grau (demais espécies). Nessa região ocorrem em geral dois a três feixes vasculares de menor calibre, adjacentes ao feixe mediano e posicionados lateralmente a este, ou ainda dois laterais e um a dois abaixo do mesmo, em direção à face abaxial, como em R. megaphylla (Fig. 46). Apenas $R$. angustifolia e R. guianensis (Fig. 43) não apresentam esses feixes menores adjacentes.

A presença de dois feixes adjacentes ao mediano foi referida para Raddia brasiliensis (sob Olyra floribunda Raddi) por Brandis (1907), Vieira et al. (2002), além de Renvoize (1985), que indicou essa condição como padrão anatômico do gênero. Entretanto, no presente trabalho, foi encontrada uma considerável variação em relação a este padrão (Tab. 3).

Variação no número de feixes adjacentes ao feixe mediano entre espécies de um mesmo gênero de bambus herbáceos foi previamente citada para Lithachne (Paisooksantivatana 1992). Dentre os materiais aqui analisados, foi encontrada variação 
também entre as espécies de Sucrea, Olyra, Pariana, Eremitis Döll e Parodiolyra, ocorrendo de um a dois feixes adjacentes, ou ausentes.

Raddia angustifolia, R. brasiliensis (Fig. 44), $R$. distichophylla, R. portoi (Fig. 47) e R. stolonifera (Fig. 48) apresentam até cinco camadas de células parenquimáticas incolores adaxiais, acima do feixe vascular mediano, enquanto as demais espécies possuem seis ou mais. A quantidade de parênquima incolor que ocorre nesta região e a posição deste tecido definem a forma da nervura central, além de torná-la mais proeminente para uma das faces, o que é visualizado externamente como uma saliência.

Feixes de fibras esclerenquimáticas estão sempre associados à região da nervura central, localizados tanto junto à face adaxial quanto à face abaxial da epiderme. Na maioria das espécies de Raddia, essas fibras estão isoladas do feixe vascular mediano por camadas de células parenquimáticas, como observado em $R$. angustifolia, $R$. brasiliensis, $R$. megaphylla (Fig. 46), R. soderstromii e $R$. stolonifera. Nas demais espécies de Raddia (Fig. 45, 47), assim como nos outros gêneros analisados da tribo Olyreae, estas fibras se ligam ao feixe vascular mediano através de extensão do esclerênquima abaxial.

Importância dos caracteres da anatomia foliar na taxonomia de Raddia - Os caracteres observados nas espécies estudadas concordam com a caracterização anatômica típica da subfamília Bambusoideae. Considerando o gênero Raddia, os dados aqui apresentados ampliam a variação anteriormente citada na literatura, o que era esperado, tendo em vista que apenas materiais de $R$. brasiliensis haviam sido estudados. A pouca variação registrada na anatomia foliar de bambus, ressaltada por autores anteriores, torna seu uso pouco consistente para fins taxonômicos, quando utilizados isoladamente. Porém, padrões anatômicos característicos para algumas espécies foram visualizados em Raddia, em maior ou menor grau. Dentre as espécies analisadas, Raddia megaphylla e $R$. guianensis apresentaram maior número de caracteres anatômicos diagnósticos. Por outro lado, estas espécies demonstraram estrutura anatômica mais variável, em materiais oriundos de diferentes populações.

Raddia brasiliensis, $R$. megaphylla, $R$. lancifolia, $R$. soderstromii e $R$. stolonifera formam um complexo específico (complexo Raddia brasiliensis), o qual foi recentemente estudado do ponto de vista morfométrico e genético por Oliveira et al. (2008). Os caracteres anatômicos foram considerados inconsistentes para apoiar a separação destas espécies. Porém, dentre as nove espécies de Raddia, tricomas curtos (prickles) na face abaxial da epiderme ocorrem apenas nos representantes deste complexo. O padrão de distribuição das papilas na face abaxial da epiderme "densamente agrupadas em faixas laterais às zonas costais", foi confirmado para as mesmas, com exceção de $R$. stolonifera. Essa espécie apresenta papilas ao longo de toda a superfície abaxial e também na face adaxial, porém nesta face, são papilas pouco conspícuas, com distribuição apenas no centro das zonas intercostais, semelhante ao observado em $R$. distichophylla e em alguns materiais de $R$. guianensis. Estas três espécies são macromorfologicamente semelhantes por apresentarem número elevado de folhas (sempre mais de dez) por colmo e inflorescências masculinas e femininas apenas axilares, diferindo nesse aspecto das demais espécies congenéricas. Raddia guianensis, entretanto, é a única que apresenta a nervura central fortemente projetada para a face adaxial, com feixe mediano deslocado para a face abaxial, e sem feixes adjacentes.

Raddia angustifolia e $R$. portoi habitam ambientes semelhantes e também são muito próximas macromorfologicamente. Neste caso, a anatomia foliar contribuiu para sua separação, principalmente na estrutura da nervura central. $\mathrm{O}$ feixe vascular mediano está deslocado para a face abaxial e feixes adjacentes a este estão ausentes em $R$. angustifolia. Além disso, nessa espécie a bainha parenquimática perivascular circunda todo o feixe, não sendo interrompida pelo esclerênquima. Raddia portoi apresenta dois feixes adjacentes ao mediano e fibras de esclerênquima interrompendo a bainha perivascular, distinguindo-se ainda de $R$. angustifolia pelas células do clorênquima com invaginações profundas e células fusóides retangulares.

Quanto à delimitação do gênero Raddia, os caracteres indicados por Renvoize (1985) foram confirmados, embora com algumas variações, principalmente em relação aos feixes adjacentes ao mediano da nervura central. Com base nos dados disponíveis, pode-se dizer que não é possível separar Raddia dos gêneros próximos, utilizando apenas caracteres da anatomia foliar.

Foram considerados de maior valor taxonômico, do ponto de vista da anatomia foliar, os seguintes caracteres: forma da nervura central em corte transversal, posição do feixe vascular mediano, número de feixes vasculares adjacentes ao mediano, forma das células fusóides, além da ocorrência, densidade e 
distribuição das papilas nas células longas da epiderme, conforme pode ser verificado na Tab. 3 .

Considerações ecológicas - Judziewicz et al. (1999) afirmaram que a anatomia foliar e a estrutura micromorfológica da epiderme das folhas dos representantes de Bambusoideae estão intimamente relacionadas à sua função fotossintética. Os aspectos revelados através do estudo da anatomia foliar das espécies de Raddia demonstraram ainda que alguns desses caracteres estão relacionados às condições ambientais dos locais onde as plantas ocorrem.

Todas as espécies analisadas apresentam rota fotossintética $\mathrm{C} 3$, assim como as demais Bambusoideae, e a estrutura do mesofilo difere consideravelmente de outros grupos de gramíneas (Hattersley 1987), em especial no que diz respeito à presença de células invaginantes e células fusóides bem desenvolvidas. A presença de parênquima clorofiliano bem compactado dificulta o transporte gasoso entre as células desse tecido e Clark (1991) sugeriu que as células fusóides poderiam ter alguma função na captação e reserva de $\mathrm{CO}_{2}$. Embora não existam estudos que comprovem esta hipótese, além do papel na captação e reserva de $\mathrm{CO}_{2}$, essas células poderiam também realizar o transporte de $\mathrm{CO}_{2}$ do clorênquima da face adaxial para o clorênquima abaxial (Berta L. Morretes, com. pess.).

Processos fisiológicos relacionados à fotossíntese compreendem diferentes mecanismos de adaptação das plantas. No caso das Bambusoideae, as células do clorênquima apresentam invaginações que promovem o aumento da área celular (Scatena \& Scremin-Dias 2003) e provavelmente isso aumenta a absorção de luz e eficiência fotossintética. Parênquima semelhante é encontrado em outras espécies que também apresentam área foliar ou mesofilo reduzido, a exemplo de espécies de Pinus L. (Gymnospermae), segundo Scatena \& Scremin-Dias (2003). A presença de parênquima pigmentado composto por antocianinas, documentada na superfície abaxial das lâminas foliares de alguns bambus herbáceos e outras gramíneas de áreas sombreadas (Soderstrom 1982), incluindo Raddia soderstromii e $R$. brasiliensis, pode estar relacionada à maior eficiência na absorção de luz pelo mesofilo, como sugerido por Lee et al. (1979). Associado a isso está ainda a grande quantidade de corpos silicosos presentes nas duas faces da epiderme, os quais, segundo Soderstrom (1982), com base nos estudos de Kaufman et al. (1979), capturam e repassam a luz para o mesofilo, e estando presentes em grande quantidade, também aumentam a capacidade fotossintética da planta.

As espécies analisadas e os demais bambus herbáceos ocorrem exclusivamente em ambientes sombreados e são pouco tolerantes à insolação e à baixa umidade. Uma vez retirada a cobertura florestal original e ficando as plantas expostas ao sol, observa-se uma diminuição considerável no porte das mesmas e nas suas dimensões foliares. Alguns dos materiais utilizados nesta análise foram coletados nessas condições ecológicas consideradas extremas para o grupo, em florestas altamente desmatadas, como os exemplares de Raddia soderstromii Oliveira 978 e Oliveira 722. Nessas populações, foi verificado que as plantas encontradas crescendo à sombra de árvores ou pequenos arbustos apresentavam maior porte $\mathrm{e}$ lâminas foliares maiores do que àquelas que cresciam totalmente ao sol, menores em todas as dimensões das estruturas vegetativas.

Segundo Taiz \& Zeiger (1998), plantas típicas de locais sombreados apresentam uma menor quantidade de camadas de parênquima clorofiliano, o que foi confirmado nas espécies estudadas. No entanto, as plantas que foram coletadas em áreas com maior exposição ao sol não apresentaram diferenças consideráveis em relação ao padrão anatômico observado nas demais amostras, coletadas exclusivamente na sombra. Deste modo, embora secundariamente expostas a condições extremas, e ainda que tenha sido observada uma evidente modificação macromorfológica nas plantas, especialmente no porte e outras dimensões vegetativas, a estrutura anatômica não foi alterada nos materiais analisados, quando comparadas lâminas de indivíduos coletados sob as duas diferentes condições.

Davila \& Clark (1990) mencionaram que em Sorgastrum Nash (Poaceae, Panicoideae), a presença e a densidade de papilas nas células epidérmicas podem estar correlacionadas com a distribuição geográfica das espécies. Diferentemente, em Raddia, estes caracteres foram mais associados ao tipo florestal onde as espécies ocorrem do que propriamente à sua distribuição. Papilas bem desenvolvidas e abundantes na face adaxial da epiderme foram encontradas exclusivamente nos espécimes ocorrentes em florestas secas. Nas espécies ocorrentes em florestas úmidas, ocorrem nessa face apenas papilas inconspícuas, ou as mesmas estão ausentes. Com base na análise anatômica de materiais de Dactylis L. (Poaceae, Pooideae), Wilson (1977 apud Sahuquillo \& Lumaret 
1995) mencionou que células epidérmicas papilosas desempenham importante função no uso eficiente da água atmosférica, sendo as mesmas registradas em plantas ocorrentes em áreas expostas a altas temperaturas. Deste modo, estas papilas podem também estar relacionadas à proteção da epiderme contra o dessecamento.

\section{Agradecimentos}

Ao Conselho Nacional de Desenvolvimento Científico e Tecnológico (CNPq), Fundação de Amparo à Pesquisa do Estado da Bahia (FAPESB) e à ASPT (American Society of Plant taxonomists), pelo auxílio financeiro aos trabalhos de campo; ao CNPq, pela bolsa de Doutorado concedida a Reyjane P. Oliveira; ao CNPq e FAPESB, pelas bolsas de Produtividade em Pesquisa concedidas a Hilda M. Longhi-Wagner e Kelly R.B. Leite; a Marcos C. Dórea, pelo auxílio na revisão do texto e edição das imagens.

\section{Referências bibliográficas}

Amarasinghe, V. \& Watson, F.L.S. 1988. Comparative ultrastructure of microhairs in grasses. Botanical Journal of the Linnean Society 98: 303-319.

Brandis, D. 1907. Remarks on the structure of Bamboo leaves. Transactions of the Linnean Society London Botany 7: 69-89.

Brown, W.V. 1958. Leaf anatomy in grass systematics. Botanical Gazette 119: 170-178.

Calderón, C.E. \& Soderstrom, T.R. 1967. Las gramineas tropicales afines a Olyra L. Atas do Simpósio sobre a Biota Amazônica 4: 67-76.

Calderón, C.E. \& Soderstrom, T.R. 1973. Morphological and anatomical considerations of the grass subfamily Bambusoideae based on the new genus Maclurolyra. Smithsonian Contributions to Botany 11: 1-55.

Clark, L.G.; Davidse, G. \& Ellis, R.P. 1989. Natural hybridization in bamboos: evidence from Chusquea sect. Swallenochloa (Poaceae: Bambusoideae). National Geographic Research 5: 459-476.

Clark, L.G. 1991. The function of fusoid cells in bamboos: an hypothesis. American Journal of Botany 78: 22 (Abstracts).

Clayton, W.D. \& Renvoize, S.A. 1986. Genera graminum: grasses of the world. Kew, Royal Botanic Gardens.

Davila, P. \& Clark, L.G. 1990. Scanning Electron Microscopy Survey of Leaf Epidermis of Sorghastrum (Poaceae: Andropogoneae). American Journal of Botany 77: 499-511.

Ellis, R.P. 1976. A procedure for standardizing comparative leaf anatomy in the Poaceae I. The leaf-blade as viewed in transverse section. Bothalia 12: 65-109.
Ellis, R.P. 1979. A procedure for standardizing comparative leaf anatomy in the Poaceae II. The epidermis as seen in surface view. Bothalia 12: 641-671.

Ellis, R.P. 1987. A review of comparative leaf blade anatomy in the sistematics of the Poaceae: the past twenty-five years. Pp. 3-10. In: T.R. Soderstrom; K.W. Hilu; C.S. Campbell \& M.E. Barkworth (eds.). Grass Systematics and Evolution. Washington, D.C., Smithsonian Institution Press.

GPWG (Grass Phylogeny Working Group). 2001. Phylogeny and subfamilial classification of the grasses (Poaceae). Annals of the Missouri Botanical Garden 88: 373-457.

Hattersley, P.W. 1987. Variations in photosynthetic pathway. Pp. 49-64. In: T.R. Soderstrom; K.W. Hilu; C.S. Campbell \& M.E. Barkworth (eds.). Grass Systematics and Evolution. Washington, D.C., Smithsonian Institution Press.

Hilu, K.W. 1984. Leaf epidermis of Andropogon sect. Leptopogon (Poaceae) in North America. Systematic Botany 9: 27-257.

Holmgren, P.K. \& Holmgren, N.H. 1998. Index Herbariorum on the Internet. Disponível em http://sciweb.nybg.org/ science2/IndexHerbariorum.asp (Acesso em: 20/10/2005).

Johansen, D.A. 1940. Plant microthechine. New York, McGraw-Hill Book Co. Inc.

Judziewicz, E.J.L.; Clark, L.G.; Londoño, X. \& Stern, M.J. 1999. American Bamboos. Washington, D.C., Smithsonian Institution Press.

Kaufman, P.B.; Tateoka, Y. \& Carlson, T.J. 1979. Studies on silica deposition in sugarcane (Saccharum spp.) using scanning electron microscopy, energy-dispersive $\mathrm{x}$-ray analysis, neutron activation analysis and light microscopy. Phytomorphology 29: 185-193.

Lee, D.W.; Lowery, J.B. \& Stone, B.C. 1979. Abaxial anthocyanin layer in leaves of tropical rain forest plants: enhancer of light capture in deep shade. Biotropica 11: 70-77.

Macêdo, N.A. 1997. Manual de técnicas em histologia vegetal. Feira de Santana, Universidade Estadual de Feira de Santana.

Metcalfe, C.R. 1956. Some thoughts on the structure of Bamboo leaves. Botanical Magazine 69: 391-400.

Metcalfe, C.R. 1960. Anatomy of the Monocotyledons. I Gramineae. Oxford, Clarendon Press.

Morrone, O. \& Zuloaga, F.O. 1991. Revision del género Streptostachys (Poaceae: Panicoideae), su posicion sistemática dentro de la tribu Paniceae. Annals of the Missouri Botanical Garden 78: 359-376.

Oliveira, R.P.; Borba, E.L. \& Longhi-Wagner, H.M. 2008. Morphometrics of herbaceous bamboos of the Raddia brasiliensis complex (Poaceae "Bambusoideae"): implications for the taxonomy of the genus and new species from Brazil. Plant Systematics and Evolution 270: $159-182$.

Page, V.M. 1947. Leaf anatomy of Streptocheta and relation of this genus to the bamboos. Bulletin of the Torrey Botanical Club 74: 232-239. 
Paisooksantivatana, Y. \& Pohl, R.W. 1992. Morphology, anatomy and citology of the genus Lithachne (Poaceae: Bambusoideae). Revista de Biología Tropical 40: 47-72.

Palmer, P.G. \& Tucker, A.E. 1981. A scanning electron microscopy survey of the epidermis of East African grasses I. Smithsonian Contributions to Botany 49: 1-84.

Peixoto, A.L. \& Silva, I.M. 1997. Tabuleiro forests of Northern Espirito Santo South-eastern Brazil. In: S.D. Davis; V.H. Heywood; O.H. Macbryde \& A.C. Hamilton (eds.). Centres of Plant Diversity: A guide Strategy for their Conservation 3: 369-372.

Prado, D.E. 2000. Seasonally dry forests of tropical South America: from forgotten ecosystems to a new phytogeographic unit. Edinburgh Journal of Botany 57: 437-461.

Piperno, D.R. \& Pearsall, D.M. 1998. The sílica bodies of tropical American grasses: morphology and taxonomy, and implications for grass Systematics and fossil phtolith identification. Smithsonian Contributions to Botany 85: 1-40.

Prat, H. 1936. La systématique des Graminées. Annales des Sciences Naturelles Botanique 18: 165-258.

Renvoize, S.A. 1985. A survey of leaf blade anatomy in grasses V. The Bamboo allies. Kew Bulletin 40: 509-535.

Renvoize, S.A. 1987. A survey of leaf blade anatomy in grasses X. Bambuseae. Kew Bulletin 42: 201-207.

Roeser, K.R. 1972. Die nadel Schwarzkiefer. Massen-produkt und kunstwerk der nature. Mikrokosmos 61: 33-36.

Sahuquillo, E. \& Lumaret, R. 1995. Variation in the Subtropical group of Dactylis glomerata L. - 1. Evidence from allozyme polymorphysm. Biochemical Systematics and Ecology 23: 407-418.

Sánchez-Ken, J.G.; Clark, L.G.; Kellogg, E.A. \& Kay, E.E. 2007. Reinstatement and Emendation of Subfamily Micrairoideae (Poaceae). Systematic Botany 32: 71-80.
Scatena, V.L. \& Scremin-Dias, E. 2003. Parênquima, colênquima e esclerênquima. Pp. 109-127. In: B. Appezzato-da-Glória \& S.M. Carmello-Guerreiro (eds.). Anatomia Vegetal. Viçosa, Editora Universidade Federal de Viçosa.

Soderstrom, T.R. 1982. Cryptochloa dressleri (Poaceae), a new bambusoid grass from Panama. Brittonia 34: 25-29.

Soderstrom, T.R. \& Ellis, R.P. 1987. The position of bamboo genera and allies in a system of grasses classification. Pp. 225-238. In: T.R. Soderstrom; K.W. Hilu; C.S. Campbell \& M.E. Barkworth (eds.). Grass Systematics and Evolution. Washington, D.C., Smithsonian Institution Press.

Taiz, L. \& Zeiger, E. 1998. Plant Phisiology. Second edition. Sinauer Associates Inc. Publishers. Suderland, Massachusetts. p. 227-249.

Tateoka, T.; Inoue, S. \& Kawano, S. 1959. Notes on some grasses. IX: Systematic significance of bicellular microhairs of leaf epidermis. Botanical Gazette 121: 80-91.

Thomas, W.W. 2003. Natural vegetation types in Southern Bahia. Pp. 1-4. In: P.I. Prado; E.C. Landau; R.T. Moura; L.P.S. Pinto; G.A.B. Fonseca \& K. Alger (orgs.). Corredor de Biodiversidade da Mata Atlântica do Sul da Bahia. Publicação em CD Rom, Ilhéus, IESB / CI / CABS / UFMG / UNICAMP.

Veloso, H.P.; Rangel Filho, A.L.R. \& Lima, J.C.A. 1991. Classificação da vegetação brasileira adaptada a um sistema universal. Rio de Janeiro, Instituto Brasileiro de Geografia e Estatística.

Vieira, R.C.; Gomes, D.M.S.; Sarahyba, L.S. \& Arruda, R.C.O. 2002. Leaf anatomy of three herbaceous bamboo species. Brazilian Journal of Biology 62: 907-922.

Zhang, W. \& Clark, L.G. 2000. Phylogeny and classification of the Bambusoideae (Poaceae). Pp. 35-39. In: S.W.L. Jacobs \& J. Everert (eds.). Grass Systematics and Evolution. Melbourne, CSIRO. 